\title{
Investigating the potential of clinical and biochemical markers to diagnose functional hypothalamic amenorrhoea in females with amenorrhoea: a retrospective observational study.
}

\author{
Sara Abou Sherif ${ }^{1}$, Rebecca Newman ${ }^{1}$, Sara Haboosh ${ }^{1}$, Ahmed Al-Sharefi ${ }^{1}$, Nikoleta \\ Papanikolaou $^{1}$, Lisa J Webber ${ }^{1}$, Stephen Franks ${ }^{1}$, Waljit S Dhillo ${ }^{1}$, and Channa Jayasena ${ }^{1}$ \\ ${ }^{1}$ Imperial College London
}

July 16, 2020

\begin{abstract}
Objective: Functional hypothalamic amenorrhoea (FHA) is a common cause of amenorrhoea, but few non-specialist clinicians are able to diagnose affected women. The aim of this study was to investigate the clinical and biochemical features of FHA, compared to that of polycystic ovarian syndrome (PCOS) and assess the diagnostic performance of the different parameters for differentiating between the two conditions. Design: A retrospective observational study Setting: Specialist reproductive endocrine gynaecology clinic, St Mary's Hospital, London, UK Population: Women diagnosed with FHA and PCOS following specialist assessment. Methods: Clinical and biochemical data were collected from electronic hospital data base. Results: Compared with PCOS, women with FHA had significantly lower body mass index (BMI) $(20.1 \pm 2.9 \mathrm{vs} 31.1 \pm 7.8 \mathrm{~kg} / \mathrm{m} 2, \mathrm{P}<0.0001)$ and a thinner endometrium $(3.75 \pm 2.23$ vs $6.82 \pm 3.32 \mathrm{~mm}, \mathrm{P}<0.0001)$. Women with FHA had significantly lower luteinising hormone ( $\mathrm{LH})(3.46 \pm 7.31$ vs $8.79 \pm 4.98 \mathrm{IU} / \mathrm{L}, \mathrm{P}<0.0001)$, as well as lower LH: follicle stimulating hormone (FSH) ratio, estradiol, thyroid-stimulating, free thyroxine and prolactin levels; there was no significant difference in FSH levels. Low BMI had the greatest predictive performance for FHA (area under the curve [AUC]; 0.93, P <0.001), followed by low estradiol (AUC 0.89, $\mathrm{P}<0.001$ ), low LH (AUC 0.88, P<0.001) and LH:FSH ratio (AUC 0.86, P<0.001). Conclusions: Our data provides quantification for diagnostic accuracy of clinical parameters to differentiate FHA from PCOS, namely low BMI, estradiol, LH and LH:FSH ratio. These data could help clinicians more reliably diagnose FHA in women with secondary amenorrhoea. Key words: Amenorrhoea, Hypogonadism, Polycystic Ovarian Syndrome, Luteinising Hormone
\end{abstract}

Title

Investigating the potential of clinical and biochemical markers to diagnose functional hypothalamic amenorrhoea in females with amenorrhoea: a retrospective observational study.

\section{Authors}

Sara Abou Sherif ${ }^{1,2}$, Rebecca Newman ${ }^{1}$, Sara Haboosh ${ }^{3}$, Ahmed Al-Sharefi ${ }^{1}$, Nikoleta Papanikolaou ${ }^{1}$, Lisa $\mathrm{J}_{\text {Webber }}{ }^{2}$, Stephen Franks ${ }^{2}$, Waljit S Dhillo ${ }^{1,3}$ and Channa N Jayasena ${ }^{1,2}$

1. Section of Investigative Medicine, Department of Metabolism, Digestion and Reproduction, Hammersmith Hospital, London

2. Department of Gynaecology, St Mary's Hospital London

3. Department of Endocrinology, Hammersmith Hospital, London

\section{Correspondence and reprint requests:}

Dr Channa N Jayasena 
Section of Investigative Medicine, Department of Metabolism, Digestion and Reproduction

Hammersmith Hospital

Du Cane Road

London W12

c.jayasena@imperial.ac.uk

\section{Running title}

Clinical and Biochemical Insights of FHA versus PCOS

\section{Structured Abstract}

Objective: Functional hypothalamic amenorrhoea (FHA) is a common cause of amenorrhoea, but few nonspecialist clinicians are able to diagnose affected women. The aim of this study was to investigate the clinical and biochemical features of FHA, compared to that of polycystic ovarian syndrome (PCOS) and assess the diagnostic performance of the different parameters for differentiating between the two conditions.

Design: A retrospective observational study

Setting: Specialist reproductive endocrine gynaecology clinic, St Mary's Hospital, London, UK

Population: Women diagnosed with FHA and PCOS following specialist assessment.

Methods: Clinical and biochemical data were collected from electronic hospital data base.

Results : Compared with PCOS, women with FHA had significantly lower body mass index (BMI) (20.1 \pm 2.9 vs $\left.31.1 \pm 7.8 \mathrm{~kg} / \mathrm{m}^{2}, \mathrm{P}<0.0001\right)$ and a thinner endometrium $(3.75 \pm 2.23$ vs $6.82 \pm 3.32 \mathrm{~mm}, \mathrm{P}<0.0001)$. Women with FHA had significantly lower luteinising hormone (LH) (3.46 47.31 vs $8.79 \pm 4.98 \mathrm{IU} / \mathrm{L}, \mathrm{P}<0.0001)$, as well as lower LH: follicle stimulating hormone (FSH) ratio, estradiol, thyroid-stimulating, free thyroxine and prolactin levels; there was no significant difference in FSH levels. Low BMI had the greatest predictive performance for FHA (area under the curve $[\mathrm{AUC}]$; 0.93, $\mathrm{P}<0.001$ ), followed by low estradiol (AUC 0.89, $\mathrm{P}<0.001$ ), low LH (AUC 0.88, $\mathrm{P}<0.001$ ) and LH:FSH ratio (AUC 0.86, $\mathrm{P}<0.001$ ).

\section{Conclusions :}

Our data provides quantification for diagnostic accuracy of clinical parameters to differentiate FHA from PCOS, namely low BMI, estradiol, LH and LH:FSH ratio. These data could help clinicians more reliably diagnose FHA in women with secondary amenorrhoea.

Key words: Amenorrhoea, Hypogonadism, Polycystic Ovarian Syndrome, Luteinising Hormone

Tweetable abstract: Low BMI, estradiol, LH and LH:FSH ratio are most effective at distinguishing FHA from PCOS.

\section{Introduction}

Functional hypothalamic amenorrhoea (FHA) is a common cause of amenorrhoea and anovulation ${ }^{1,}$; it is responsible for up to $3 \%$ of primary ${ }^{2}$ and $33.5 \%$ of secondary amenorrhoea cases. ${ }^{1}$ FHA is a form of hypogonadotropic hypogonadism caused by hypothalamic-pituitary-ovarian (HPO) axis dysregulation. It is characterised by estradiol deficiency due to reduced hypothalamic gonadotrophin-releasing hormone (GnRH) secretion. Common causes include stress, weight loss and excessive exercise. ${ }^{1}$

Early FHA diagnosis is crucial to prevent complications such as osteoporosis and infertility secondary to anovulation. FHA features, such as low body mass index (BMI) and psychological stress, can cause complications, if pregnancy does occur; mothers with low BMI are more likely to have miscarriages ${ }^{3}$, give birth prematurely and have low birth weight babies. ${ }^{4}$ Furthermore, prolonged hypoestrogenemia reduces bone 
mineral density (BMD), causing osteopenia and osteoporosis and has significant negative impacts on the cardiovascular system.

$5-7$

Eighty three percent of FHA cases are reversible, when causative factors are addressed.

8 The 2017 Endocrine Society Guidelines recommend first-line treatment of FHA should aim to energy availability by improving nutrition, supporting weight gain and reducing exercise.

${ }^{9}$ However, FHA diagnosis may be complicated by an indistinct clinical picture and confusion with another common cause of menstrual disturbance: polycystic ovary syndrome (PCOS). The typical hormone profile in PCOS has some reported distinctions from FHA, namely: elevated LH: follicle-stimulating hormone (FSH) ratio and free testosterone; reduced sex hormone binding globulin; and normal estradiol, prolactin, cortisol and thyroid hormones. ${ }^{10}$ However, many women with FHA or PCOS display non-typical hormone profiles. Furthermore, up to $40 \%$ of women with FHA have features of polycystic ovarian morphology (PCOM) on ultrasound.

11,12 PCOS usually presents with oligomenorrhea or eumenorrhea but can also present with amenorrhoea. In contrast to FHA, PCOS treatment involves controlling hyperandrogenism symptoms and reducing metabolic risk. The Endocrine Society recommends hormonal contraceptives in PCOS to regulate periods ${ }^{13}$, however the oral contraceptive pill is not recommended for FHA since they provide inferior bone mineralisation, when compared with hormone replacement therapy.

${ }^{9}$ Failure to detect FHA can also result in failure to address underlying psychological comorbidities. Few studies have compared the clinical and biochemical features of FHA with other causes of amenorrhoea and there remains limited data on the diagnostic performance of parameters such as estradiol, LH and BMI, in distinguishing between FHA and PCOS.

Our study aimed to investigate the clinical and biochemical features of FHA and comparing it to that of women with PCOS. Additionally, we explored the diagnostic performance of these parameters in distinguishing between FHA and PCOS.

\section{Methods:}

\section{Study population}

A retrospective analysis of patients seen in a reproductive endocrine clinic at St Mary's Hospital, London, UK. 100 consecutive women with FHA were seen by three experienced endocrinologists (Dr Channa N Jayasena, Professor Stephen Franks and Miss Lisa J Webber) between January 2016 and February 2020. Due to the lack of universally accepted criteria for diagnosing FHA, FHA diagnosis was made on clinical suspicion by the three consultant physicians. Women with FHA and concurrent PCOS features were also noted. The database was also interrogated to identify 100 consecutive patients with a confirmed PCOS diagnosis between November 2014 and February 2020. PCOS was diagnosed in accordance with the Rotterdam Criteria (2003). ${ }^{14}$ Patients were excluded if taking contraceptive medication or using a contraceptive device at the time of blood testing, to reduce the influence of these on hormone levels.

\section{Data collection}

Data were collected from the National Health (NHS) Service Cerner ${ }^{\circledR}$ database and a private healthcare database (Carebit, London UK). Patient demographic data collected, included age and ethnicity. Clinical data was extracted from patient notes and referral letters, including menstrual frequency; hyperandrogenism and hypoestrogenism symptoms; exercise history; weight loss preceding amenorrhoea; psychological stress; and occupation. Occupations were stratified using International Standard Classification of Occupations 2008 (ISCO-08). ${ }^{15}$ Data was collected on patient medical history, including fractures, eating disorders (ED), psychological comorbidities and family history. Patients BMI was collected and used to categorise patients as: underweight $\left(<18.5 \mathrm{~kg} / \mathrm{m}^{2}\right)$; healthy $\left(18.5-24.9 \mathrm{~kg} / \mathrm{m}^{2}\right)$; overweight $\left(25-29.9 \mathrm{~kg} / \mathrm{m}^{2}\right) ;$ obese $\left(30-39.9 \mathrm{~kg} / \mathrm{m}^{2}\right)$; 
or morbidly obese $\left([?] 40 \mathrm{~kg} / \mathrm{m}^{2}\right)$. Ultrasonography reports provided endometrial thickness and polycystic ovarian morphology (PCOM) data. Reports provided BMD and Z-score of L2-L4 segment and femora from dual energy X-ray absorptiometry (DEXA) scans. Blood results either from the first clinic visit or GP referral letter were examined for $\mathrm{LH}$ [reference value $>3 \mathrm{IU} / \mathrm{L}$ ] and FSH [ reference value $>6 \mathrm{IU} / \mathrm{L}$ ] (used to calculate LH:FSH ratio [reference value $<2$ ]), estradiol [reference value $>100 \mathrm{pmol} / \mathrm{L}$ ], thyroid-stimulating hormone (TSH) [reference range 0.4-4.0mU/L], free T4 (fT4) [reference range 9.0-25.0pmol/1], and prolactin [reference range $45-375 \mathrm{IU} / \mathrm{mL}$ ]. Given the retrospective nature of this study, it was expected that a significant proportion of patients would have missing data; to overcome this comparison between the FHA and PCOS groups were only performed when the majority ([?]50\%) of patients had data available.

Statistical analysis:

Statistical analysis was performed using IBM(r) SPSS Statistics (V.1). Descriptive statistics were computed for all study variables. Kolmogorov-Smirnov normality tests were performed. Continuous data was reported as mean +- standard deviation and analysed using unpaired, two-tailed T-tests. Categorical data was analysed using Fisher's Exact Test. Receiver Operator Characteristics (ROC) graphs were plotted and analysed; area under the curve (AUC) was used to quantify the diagnostic performance of each parameter. $\mathrm{AUC}=1$ indicated perfect distinction between FHA and PCOS, whilst $\mathrm{AUC}=0.5$ indicated no different from random selection. $\mathrm{P}<0.05$ was considered statistically significant.

\section{Results}

Functional hypothalamic amenorrhoea characteristics.

The mean age of 100 women with FHA was $27.7+-6.25 ; 14$ of those had suspected concomitant PCOS. The average duration of menstrual disturbance in 80 patients was $2.98+-3.24$ years. Exercise history was recorded in 81 women with FHA; 76 (94\%) exercised regularly. There was a history of eating disorder in $52.5 \%$ of those with available ED data. Of those reporting no history of ED, 9 reported dietary restrictions, with 4 practicing veganism and 1 case each of lactose intolerance, low FODMAP diet, gluten-free diet, intermittent fasting and pescatarianism. Psychological stress was reported by the majority 59/65 (91\%) of women with FHA. Occupation data was available for 60 women with FHA; when categorised according to the ISCO-08 structure, the majority had high ranking occupations. Further details about the characteristics of women with FHA are summarised in supporting table S1.

Clinical, biochemical and ultrasound comparison of FHA and PCOS.

Comparisons between women with FHA and PCOS are summarised in Table 1. Further details about the characteristics of PCOS patients are summarised in supporting table S2. Dot plots comparing parameters between groups are displayed in figure 1. Women with FHA had a significantly lower mean BMI than women with PCOS. This finding was further supported by a significant association between reproductive disorder type and BMI category $(\mathrm{P}<0.0001) ; 23 / 81(28 \%)$ of women with FHA had a BMI $<18.5 \mathrm{~kg} / \mathrm{m}^{2}$ compared to only $2 / 81(2.5 \%)$ of women with PCOS. Significantly fewer women with FHA $25 / 51(49 \%)$ than women with PCOS 78/82 (95\%) reported hyperandrogenism symptoms $\mathrm{P}<0.0001)$. There is a statistically significant difference in most of the studied hormonal parameters between the two group populations. Women with FHA have lower LH, estradiol, LH:FSH ratio, TSH and FT4 as well as prolactin levels. In addition, endometrial thickness was considerably thinner in the FHA group.

Diagnostic performance of clinical, biochemical and ultrasound parameters for predicting FHA.

Low BMI $\left(<18.5 \mathrm{~kg} / \mathrm{m}^{2}\right)$ demonstrated the greatest diagnostic performance for FHA (AUC; 0.93, P $<0.001$ ), followed by a low estradiol level $(<100 \mathrm{pmol} / \mathrm{L})$ (AUC; 0.89, P<0.001), low LH $(<3 \mathrm{IU} / \mathrm{L})(0.88, \mathrm{P}<0.001)$ and low LH:FSH ratio $(<2)(0.86, \mathrm{P}<0.001)$. Further details about diagnostic performance of biochemical and clinical parameters displayed in figure 2 .

\section{Discussion}




\section{Main findings}

FHA is one of the most common reproductive disorders in females. However, many patients experience delay in diagnosis of FHA due to limited clinical knowledge of its common features. This retrospective study demonstrates the significant impact of FHA on women's health; associated psychological comorbidities, including EDs, anxiety and depression, occurred at rates of approximately 20\%, whilst the effects of hypoestrogenemia on BMD were evident as over $50 \%$ of women who received DEXA scans were diagnosed with osteopenia or osteoporosis. Our findings demonstrate that the established FHA risk factors of stress, excessive exercise and weight loss remain important clinical features. We quantitatively demonstrate that low BMI, estradiol, LH and LH:FSH ratio distinguish women with FHA from women with PCOS, most effectively. Our findings call for careful consideration of the above clinical and biochemical features to first suspect and second, diagnose FHA and differentiate from other common causes of menstrual disturbances such as PCOS.

\section{Strengths and Limitations}

Due to the retrospective design, data collection was restricted to available content on databases, which resulted in missing data for various indices, limiting statistical comparison between the two groups. Furthermore, we were unable to assess psychological comorbidities such as EDs, depression and anxiety using scoring scales, which is the preferred method of assessment in most other FHA studies. In the absence of a psychological diagnosis, more subtle traits and behaviours may have gone undetected in our study. We also recognise that concomitant PCOS cannot be excluded in some women with FHA; in our study clinicians suspected underlying PCOS in 14 women with FHA. Previous studies, have demonstrated that PCOS-like abnormalities, including elevated anti-Mullerian hormone and PCOM on ultrasound, may be an incidental finding in up to $40 \%$ of women with FHA and $10 \%$ may have co-existing PCOS.

11,12 Thus, some women with FHA and low a BMI may represent a subgroup of "suppressed PCOS", which may be uncovered with weight gain and lifestyle changes, ensuing hypothalamic-pituitary-ovarian (HPO) axis recovery. ${ }^{16}$ In an attempt to clarify this clinical dilemma, various retrospective studies have demonstrated lower incidence of hyperandrogenism, lower mean LH levels and sex hormone binding globulins (indicating insulin resistance), in women with FHA and underlying PCOS.

17,18 There remains, however, a lack of adequately powered, prospective trials to investigate to what extent parameters such BMI, estradiol, LH and LH:FSH ratio, differ in this subgroup of women with FHA. A strength of this study is our large sample of women with FHA, compared to previous studies. Our study is one of few to compare women with FHA to those with PCOS, rather than eumenorrheic women.

\section{Interpretation}

Our data supports the strength of known FHA risk factors including, high-level cardiovascular exercise, psychological stress ${ }^{19}$ and weight loss preceding amenorrhoea. ${ }^{20-22}$ Fat loss and dieting decrease circulating leptin; hypoleptinemia reduces stimulation of hypothalamic neuronal networks, thus suppressing $\mathrm{GnRH}$ secretion.

${ }^{23,24}$ Despite increased exercise states, however, 21/50 and 8/50 of women with FHA who a received DEXA scan, were osteopenic and osteoporotic, respectively. We observed lower rates of reduced BMD, than those in the literature; with reported rates of osteopenia and osteoporosis as high as $83 \%$ and $33 \%$ respectively in women with FHA

25,26 ; this may have been attributed to the low rates of DEXA scanning in our study group. $50 \%$ of women with FHA reported a positive ED history, which was comparable to previously reported rates of $55 \% .{ }^{27}$

A large retrospective study investigating the potential for misdiagnosis of FHA found that $86 \%$ of lean women with FHA would have met the Rotterdam criteria for PCOS diagnosis, had FHA not been detected. 
17 Although we have highlighted the pertinent clinical features of FHA, it is important to recognise that the underlying aetiology of FHA often involves a varying degree of interacting factors and there remains a lack of consensus on what constitutes excessive exercise, significant nutrition restriction or psychological stress. This is deemed problematic in the absence of reliable investigative or biochemical diagnostic tests and the growing concerns around misdiagnosing women with FHA with PCOS.

An important finding of our study was the significantly lower BMI in women with FHA compared to those with PCOS, this is supported by previous reports. ${ }^{28}$ Whilst BMI was found to best distinguish between FHA from PCOS extremely effectively, the large range reported emphasises the importance of not ruling out PCOS or FHA based on BMI alone. The heterogenous and often insidious presentation of FHA calls for a comprehensive clinical approach, which includes combining clinical parameters with the patient's history (occupational, exercise and nutrition) to first suspect and second, diagnose FHA. A recent study by Rodino et al demonstrated $65 \%$ of fertility specialists did not screen for eating disorders during preconception assessments, despite $83.7 \%$ of fertility specialists in their study agreeing it was important to do so, this was perhaps explained by the fact that only $37.5 \%$ felt confident in their ability to recognise symptoms of an eating disorder. ${ }^{29}$ This is of particular significance given that $76.4 \%$ to $100 \%$ of patients do not disclose their eating disorder. ${ }^{30,31}$ In their retrospective study, Bradbury et al argue that lack of a detailed diet and exercise history in patients with a low BMI may result in them being misdiagnosed with PCOS.

17

Similarly, to our biochemical findings, one study comparing women with FHA with PCOS, found lower baseline LH and estradiol in women with FHA, with no difference in FSH levels. ${ }^{32}$ Low estradiol levels are typical of FHA, secondary to suppression or insufficient stimulation of the HPO axis, in which no anatomic or organic pathology can be identified. ${ }^{33}$ Elevated LH and mild FSH suppression characterises PCOS 10 whereas, whilst both gonadotropins are reduced in FHA, LH is suppressed more significantly. ${ }^{34,35}$ This likely explains why estradiol and LH were highly effective at distinguishing FHA from PCOS and why FSH was a poor distinguisher. The highly significant difference in LH between FHA and PCOS combined with the similar FSH levels meant that the LH:FSH ratio was also good at distinguishing the two conditions. Knowledge of the patient's baseline LH and FSH levels is important in the context of diagnosis but also when considering fertility treatment options. For example, the use of clomiphene citrate is unlikely to be recommended, owing to the underlying hypoestrogenic state in FHA patients. ${ }^{36}$ Nonetheless the use of exogenous gonadotrophin therapy will likely require both LH and FSH stimulation ${ }^{37}$; this would require patients to be educated on the risks of ovarian hyperstimulation syndrome (OHSS), especially in the presence of low BMI which increases sensitivity to gonadotrophin stimulation. ${ }^{38}$

\section{Conclusion}

Our study suggests that many women with FHA have a typical phenotype of excessive cardiovascular exercise, weight loss, psychological stress and reduced BMD. Psychological comorbidities including EDs, depression and anxiety were moderately prevalent. The most effective parameters distinguishing women with FHA from women with PCOS were low BMI, estradiol, LH and LH:FSH ratio. These data could be utilized to prospectively validate a standardized protocol to optimise the diagnosis and improve the management of women with FHA.

\section{Disclosure of interests}

None to declare

\section{Contribution to authorship}

SAS: contributed to design of study; analysed and interpreted the data; and drafted and revised the manuscript. RN: contributed to design of study; acquired, analysed data; and revised the manuscript. CJ: designed the study; acquired and interpreted the data; and revised the manuscript. SH, AA, NP, LW, SF and WSD: designed the study and revised the manuscript. All authors gave final approval of the version to be published. All authors agree to be accountable for all aspects of the work. 


\section{Details of ethics approval}

As a result of the retrospective design, no ethical approval was required for this study. Exception from ethical approval was confirmed by the Medical Ethics Committee (METC) from Imperial College London.

\section{Funding}

None.

\section{Acknowledgements}

WSD is funded by an NIHR Research Professorship and the NIHR Imperial Biomedical Research Centre.

\section{References:}

1. Reindollar RH, Novak M, Tho SPT, McDonough PG. Adult-onset amenorrhea: A study of 262 patients. American Journal of Obstetrics and Gynecology. 1986 Sep;155(3):531-41.

2. Current evaluation of amenorrhea. Fertility and Sterility. 2006 Nov;86(5):S148-55.

3. Maconochie N, Doyle P, Prior S, Simmons R. Risk factors for first trimester miscarriage-results from a UK-population-based case-control study. BJOG: An International Journal of Obstetrics \& Gynaecology. John Wiley \& Sons, Ltd; 2007 Feb;114(2):170-86.

4. Han Z, Mulla S, Beyene J, Liao G, McDonald SD. Maternal underweight and the risk of preterm birth and low birth weight: a systematic review and meta-analyses. International Journal of Epidemiology. 2010 Nov 20;40(1):65-101.

5. Taskin O, Gokdeniz R, Muderrisoglu H, Korkmaz M, Uryan, I, Atmaca R et al. The effects of hormone replacement therapy on echocardiographic basic cardiac functions in postmenopausal women. Human Reproduction. 1998 Sep 1;13(9): 2399-2401.

6. Losordo DW, Kearney M, Kim EA, Jekanowski J, Isner JM. Variable expression of the estrogen receptor in normal and atherosclerotic coronary arteries of premenopausal women. Circulation. 1994 Apr 1;89(4):150110.

7. Hodgin JB, Krege JH, Reddick RL, Korach KS, Smithies O, Maeda N. Estrogen receptor $\alpha$ is a major mediator of $17 \beta$-estradiol's atheroprotective effects on lesion size in Apoe-/- mice. J Clin Invest. American Society for Clinical Investigation; 2001 Feb 1;107(3):333-40.

8. Perkins R, Hall J, Martin K. Aetiology, previous menstrual function and patterns of neuro-endocrine disturbance as prognostic indicators in hypothalamic amenorrhoea. Human Reproduction. 2001;16(10): 2198-2205.

9. Gordon C, Ackerman K, Berga S, Kaplan J, Mastorakos G, Misra M.Murad, et al. Functional Hypothalamic Amenorrhea: An Endocrine Society Clinical Practice Guideline. The Journal of Clinical Endocrinology \& Metabolism. 2017;102(5):1413-1439.

10. Dumitrescu R, Mehedintu C, Briceag I, Purcarea VL, Hudita D. The polycystic ovary syndrome: an update on metabolic and hormonal mechanisms. Journal of Medicine and Life. Carol Davila - University Press; 2015 Apr;8(2):142-5.

11. Sum M, Warren MP. Hypothalamic amenorrhea in young women with underlying polycystic ovary syndrome. Fertility and Sterility. Elsevier; 2009 Dec 1;92(6):2106-8.

12. Robin G, Gallo C, Catteau-Jonard S, Lefebvre-Maunoury C Pigny P, Duhamel A et al. Polycystic Ovary-Like Abnormalities (PCO-L) in Women with Functional Hypothalamic Amenorrhea. The Journal of Clinical Endocrinology \& Metabolism. 2012;97(11): 4236-4243. 
13. Legro RS, Arslanian SA, Ehrmann DA, Hoeger KM, Murad MH, Pasquali R, et al. Diagnosis and Treatment of Polycystic Ovary Syndrome: An Endocrine Society Clinical Practice Guideline. The Journal of Clinical Endocrinology \& Metabolism. 2013 Dec;98(12):4565-92.

14. Revised 2003 consensus on diagnostic criteria and long-term health risks related to polycystic ovary syndrome. Fertility and Sterility, 2004;81(1):19-25.

15. Office IL. International standard classification of occupations: ISCO-88. 1990. [Internet]. Available from: https://www.ilo.org/wcmsp5/groups/public/—dgreports/—dcomm/— publ/documents/publication/wcms_172572.pdf

16. Aubuchon M, Liu Y, Petroski GF, Thomas TR, Polotsky AJ. The impact of supervised weight loss and intentional weight regain on sex hormone binding globulin and testosterone in premenopausal women. Systems Biology in Reproductive Medicine. Taylor \& Francis; 2016 May 18;62(4):283-9.

17. Bradbury R, Lee P, Smith H. Elevated anti-Mullerian hormone in lean women may not indicate polycystic ovarian syndrome. Australian and New Zealand Journal of Obstetrics and Gynaecology. 2017;57(5): 552-557.

18. Stepto N, Cassar S, Joham A, Hutchison S, Harrison C, Goldstein R, et al. Women with polycystic ovary syndrome have intrinsic insulin resistance on euglycaemic-hyperinsulaemic clamp. Human Reproduction. 2013;28(3): 777-784.

19. McEwen BS. Allostasis and Allostatic Load: Implications for Neuropsychopharmacology. Neuropsychopharmacol. Nature Publishing Group; 2000 Feb 1;22(2):108-24.

20. Wilmore JH, Brown CH, Davis JA. Body physique and composition of the female distance runner. Annals of the New York Academy of Sciences. John Wiley \& Sons, Ltd; 1977 Oct 1;301(1):764-76.

21. Loucks AB. Low Energy Availability in the Marathon and Other Endurance Sports. Sports Med. Springer International Publishing; 2007 Apr 1;37(4):348-52.

22. Bachmann GA, Kemmann E. Prevalence of oligomenorrhea and amenorrhea in a college population. American Journal of Obstetrics and Gynecology. Mosby; 1982 Sep;144(1):98-102.

23. Andrico S, Gambera A, Specchia C, Pellegrini C, Falsetti L, Sartori E. Leptin in functional hypothalamic amenorrhoea. Human Reproduction. 2002;17(8):2043-2048.

24. Andrisani A, Sabbadin C, Minardi S, Favaro A, Donà G, Bordin L, et al. Persistent amenorrhea and decreased DHEAS to cortisol ratio after recovery from anorexia nervosa. Gynecological Endocrinology. 4 ed. Taylor \& Francis; 2016 Dec 2;33(4):311-4.

25. Biller BM, Coughlin JF, Saxe V, Schoenfeld D, Spratt DI, Klibanski A. Osteopenia in women with hypothalamic amenorrhea: a prospective study. Obstet Gynecol. 1991 Dec;78(6):996-1001.

26. Pollock N, Grogan C, Perry M, Pedlar C, Cooke K, Morrissey D, et al. Bone-mineral density and other features of the female athlete triad in elite endurance runners: a longitudinal and cross-sectional observational study. Int J Sport Nutr Exerc Metab. Human Kinetics, Inc; 2010 Oct;20(5):418-26.

27. Warren MP, Voussoughian F, Geer EB, Hyle EP, Adberg CL, Ramos RH. Functional hypothalamic amenorrhea: hypoleptinemia and disordered eating. The Journal of Clinical Endocrinology \& Metabolism. 1999 Mar;84(3):873-7.

28. Colombo O, Pinelli G, Comelli M, Marchetti P, Sieri S, Brighenti F, et al. Dietary intakes in infertile women a pilot study. Nutr J. BioMed Central; 2009 Nov 10;8(1):53-9.

29. Rodino IS, Byrne SM, Sanders KA. Eating disorders in the context of preconception care: fertility specialists' knowledge, attitudes, and clinical practices. Fertility and Sterility. 2017 Feb;107(2):494-501.

30. Stewart DE, Raskin J, Garfinkel PE, MacDonald OL, Robinson GE. Anorexia nervosa, bulimia, and pregnancy. American Journal of Obstetrics and Gynecology. 1987 Nov;157(5):1194-8. 
31. Freizinger M, Franko DL, Dacey M, Okun B, Domar AD. The prevalence of eating disorders in infertile women. Fertility and Sterility. 2010 Jan;93(1):72-8.

32. Wang JG, Lobo RA. The complex relationship between hypothalamic amenorrhea and polycystic ovary syndrome. The Journal of Clinical Endocrinology \& Metabolism. 2008 Apr;93(4):1394-7.

33. Gordon CM. Clinical practice. Functional hypothalamic amenorrhea. N Engl J Med. 2010 Jul $22 ; 363(4): 365-71$.

34. Berga SL, Mortola JF, Girton L, Suh B, Laughlin G, Pham P, et al. Neuroendocrine aberrations in women with functional hypothalamic amenorrhea. The Journal of Clinical Endocrinology \& Metabolism. 1989 Feb;68(2):301-8.

35. Laughlin GA, Dominguez CE, Yen SS. Nutritional and endocrine-metabolic aberrations in women with functional hypothalamic amenorrhea. The Journal of Clinical Endocrinology \& Metabolism. 1998 Jan;83(1):25-32.

36. Dickey RP, Holtkamp DE. Development, pharmacology and clinical experience with clomiphene citrate. Hum Reprod Update. 1996 Nov;2(6):483-506.

37. Messinis IE. Ovulation induction: a mini review. Hum Reprod. 2005 Oct;20(10):2688-97.

38. Smith V, Osianlis T, Vollenhoven B. Prevention of Ovarian Hyperstimulation Syndrome: A Review. Obstet Gynecol Int. Hindawi; 2015;2015(2):514159-10.

Table 1. Comparing clinical and biochemical features of women with FHA versus PCOS . Abbreviations: LH, luteinising hormone; FSH, follicle-stimulating hormone; TSH, thyroid-stimulating hormone; T4, thyroxine. ${ }^{*}$ denotes where differences between FHA and PCOS groups were statistically significant at $\mathrm{p}<0.05$.

\begin{tabular}{|c|c|c|c|c|c|}
\hline Characteristic & FHA & FHA & PCOS & PCOS & $P$ value \\
\hline & $\begin{array}{l}\text { Patients } \\
\text { no. } / 100\end{array}$ & Mean \pm SD & $\begin{array}{l}\text { Patients } \\
\text { no. } / 100\end{array}$ & Mean \pm SD & \\
\hline $\begin{array}{l}\text { Age } \\
\text { Type of } \\
\text { menstrual } \\
\text { disturbance* }\end{array}$ & 100 & $27.7 \pm 6.25$ & 100 & $29.2 \pm 7.35$ & $\begin{array}{l}0.124 \\
<0.0001\end{array}$ \\
\hline $\begin{array}{l}\text { Primary } \\
\text { amenorrhoea }\end{array}$ & 4 & & 0 & & \\
\hline $\begin{array}{l}\text { Secondary } \\
\text { amenorrhoea }\end{array}$ & 90 & & 16 & & \\
\hline Oligomenorrhoea & 6 & & 56 & & \\
\hline Eumenorrhoea & 0 & & 19 & & \\
\hline Not reported & 0 & & 9 & & \\
\hline $\begin{array}{l}\text { Body mass } \\
\text { index } \\
\left(\mathrm{kg} / \mathrm{m}^{2}\right) *\end{array}$ & 81 & $20.1 \pm 2.9$ & 81 & $31.1 \pm 7.8$ & $<0.0001$ \\
\hline $\begin{array}{l}\text { Body mass } \\
\text { index } \\
\text { category } *\end{array}$ & & & & & $<0.0001$ \\
\hline $\begin{array}{l}\text { Underweight }(< \\
\left.18.5 \mathrm{~kg} / \mathrm{m}^{2}\right)\end{array}$ & 23 & & 2 & & \\
\hline $\begin{array}{l}\text { Healthy weight } \\
(18.5-24.9 \\
\left.\mathrm{kg} / \mathrm{m}^{2}\right)\end{array}$ & 54 & & 18 & & \\
\hline
\end{tabular}




\begin{tabular}{|c|c|c|c|c|c|}
\hline Characteristic & FHA & FHA & PCOS & PCOS & $P$ value \\
\hline $\begin{array}{l}\text { Overweight ( } 25- \\
\left.29.9 \mathrm{~kg} / \mathrm{m}^{2}\right)\end{array}$ & 3 & & 21 & & \\
\hline $\begin{array}{l}\text { Obese }(30-39.9 \\
\left.\mathrm{kg} / \mathrm{m}^{2}\right)\end{array}$ & 1 & & 24 & & \\
\hline $\begin{array}{l}\text { Morbidly obese } \\
\left([?] 40 \mathrm{~kg} / \mathrm{m}^{2}\right)\end{array}$ & 0 & & 16 & & \\
\hline Not reported & 19 & & 19 & & \\
\hline $\begin{array}{l}\text { Symptoms of } \\
\text { hyperandro- } \\
\text { genism* }\end{array}$ & & & & & $<0.0001$ \\
\hline Yes & 25 & & 78 & & \\
\hline No & 26 & & 4 & & \\
\hline Not reported & 49 & & 18 & & \\
\hline Symptom type & & & & & 0.116 \\
\hline Hirsutism & 12 & & 68 & & \\
\hline Acne & 16 & & 38 & & \\
\hline Hair thinning & 3 & & 13 & & \\
\hline $\begin{array}{l}\text { Ultrasound } \\
\text { features* }\end{array}$ & & & & & \\
\hline $\begin{array}{l}\text { Polycystic } \\
\text { ovarian } \\
\text { morphology* }\end{array}$ & & & & & $<0.01$ \\
\hline Yes & 33 & & 60 & & \\
\hline No & 35 & & 20 & & \\
\hline Not reported & 32 & & 20 & & \\
\hline $\begin{array}{l}\text { Endometrial } \\
\text { thickness (mm) } \\
*\end{array}$ & 60 & $3.75 \pm 2.23$ & 70 & $6.82 \pm 3.32$ & $<0.0001$ \\
\hline \multicolumn{6}{|l|}{$\begin{array}{l}\text { Blood } \\
\text { results }\end{array}$} \\
\hline $\mathrm{LH}(\mathrm{IU} / \mathrm{L}) *$ & 88 & $3.46 \pm 7.31$ & 98 & $8.79 \pm 4.98$ & $<0.0001$ \\
\hline FSH (IU/L) & 88 & $4.60 \pm 2.12$ & 97 & $4.96 \pm 1.58$ & 0.200 \\
\hline LH : FSH ratio * & 88 & $0.782 \pm 1.16$ & 97 & $1.81 \pm 0.929$ & $<0.0001$ \\
\hline $\begin{array}{l}\text { Estradiol } \\
(\mathrm{pmol} / \mathrm{L}) *\end{array}$ & 83 & $111 \pm 73.3$ & 72 & $260 \pm 212$ & $<0.0001$ \\
\hline $\mathrm{TSH}(\mathrm{mU} / \mathrm{L}) *$ & 71 & $1.41 \pm 0.610$ & 85 & $1.68 \pm 0.915$ & 0.0321 \\
\hline $\begin{array}{l}\text { Free T4 } \\
(\mathrm{pmol} / \mathrm{L}) *\end{array}$ & 61 & $11.2 \pm 1.36$ & 80 & $13.0 \pm 1.75$ & $<0.0001$ \\
\hline $\begin{array}{l}\text { Prolactin } \\
(\mathrm{IU} / \mathrm{mL}) *\end{array}$ & 74 & $183 \pm 133$ & 70 & $261 \pm 158$ & $<0.01$ \\
\hline
\end{tabular}

Figure 1. Dot plot comparisons of clinical and biochemical parameters in women with FHA versus women with PCOS. Body mass index $\mathrm{kg} / \mathrm{m}^{2}$ (BMI, A), endometrial thickness (mm) (B), luteinising hormone (LH, C), follicle-stimulating hormone; (FSH, D), luteinising hormone: follicle-stimulating hormone ratio (FSH: LH ratio, E), estradiol (F), thyroid-stimulating hormone (TSH, G), free thyroxine (fT4, $\mathrm{H}$ ) and prolactin (I) values in the functional hypothalamic amenorrhoea (FHA) and polycystic ovary syndrome (PCOS) groups. Comparisons between women with FHA and PCOS were made where $>50 \%$ of data was present and are summarised in Table $1 .{ }^{*}$ denotes where differences between FHA and PCOS groups were statistically significant at $\mathrm{p}<0.05$. Error bars represent population mean and standard deviation. 
Figure 2. Diagnostic performance of clinical and biochemical parameters for differentiating women FHA from women with PCOS. Receiver operating characteristic curves for Body mass index $\mathrm{kg} / \mathrm{m}^{2}$ (BMI, A) and endometrial thickness $(\mathrm{mm})$ (B), luteinising hormone (LH, C), follicle-stimulating hormone; (FSH, D), luteinising hormone: follicle-stimulating hormone ratio (FSH: LH ratio, E),estradiol (F), thyroid-stimulating hormone (TSH, G), free thyroxine (fT4, H) and prolactin (I) Abbreviation: AUC, area under the curve. $\mathrm{AUC}=1$ indicated perfect distinction between FHA and PCOS, whilst $\mathrm{AUC}=0.5$ indicated no different from random selection. Red dotted line $=$ performance of random chance.

\section{Hosted file}

Figure 1. .docx available at https://authorea.com/users/343486/articles/470125-investigatingthe-potential-of-clinical-and-biochemical-markers-to-diagnose-functional-hypothalamicamenorrhoea-in-females-with-amenorrhoea-a-retrospective-observational-study

\section{Hosted file}

Figure 2. .docx available at https://authorea.com/users/343486/articles/470125-investigatingthe-potential-of-clinical-and-biochemical-markers-to-diagnose-functional-hypothalamicamenorrhoea-in-females-with-amenorrhoea-a-retrospective-observational-study 